\title{
A greenhouse approach for value cultivation
}

\author{
Jens Jörn Dahlgaard, Adrian Pugna, Sabina Potra, Romeo Negrea and Marian Mocan
}

\author{
Journal Article
}

\section{Tweet}

N.B.: When citing this work, cite the original article.

This is an electronic version of an article published in:

Jens Jörn Dahlgaard, Adrian Pugna, Sabina Potra, Romeo Negrea and Marian Mocan, A greenhouse approach for value cultivation, Total quality management and business excellence (Online), 2016. 27(7-8), pp.836-852.

Total quality management and business excellence (Online) is available online at informaworldTM:

http://dx.doi.org/10.1080/14783363.2016.1202757

Copyright: Taylor \& Francis (Routledge): SSH Titles

http://www.routledge.com/

Postprint available at: Linköping University Electronic Press

http://urn.kb.se/resolve?urn=urn:nbn:se:liu:diva-131734

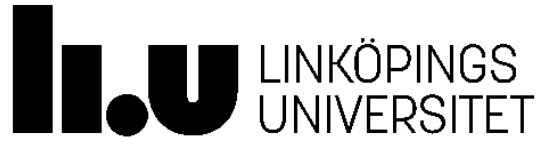




\title{
A Greenhouse Approach for Value Cultivation
}

\author{
Jens J. Dahlgaard \\ Linköping University, Sweden \\ jens.jorn.dahlgaard@liu.se \\ Adrian Pugna, Sabina Potra, Romeo Negrea, Marian Mocan \\ Politehnica University Timisoara, Romania \\ adrian.pugna@upt.ro; sabina.potra@upt.ro; romeo.negrea@upt.ro; marian.mocan@upt.ro
}

\begin{abstract}
The present paper explores design requirements to take into consideration when designing and developing new products or services. The purpose of this article is to develop a strategic approach for analysing variations between potential customer needs in order better to understand what qualities should be further cultivated before product launch. This new approach is called "A Greenhouse Approach for Value Cultivation".

Case study data of a new web based customization service for a Romanian shoe manufacturing company has been re-analysed by using questionnaire data on 166 respondents' perceptions on 14 attributes' importance and value. A non-linear regression model was developed and used to understand relations between importance and value. Such relations were used together with the Greenhouse Model to better understand the service attributes' potential life cycles if selected for further cultivation. The Greenhouse Model envisages new perspectives of the evaluation of customer needs to support strategic decision making regarding further value cultivation for profound affection (= customer delight).

Even if there is a need for further tests the suggested "Greenhouse Approach for Value Cultivation" is regarded as a new and original contribution to the theory of attractive quality creation which deepens its position in the theory of attractive quality and transforms it into a practical management tool to support new product and service design.
\end{abstract}

Keywords: HWWP model; attractive quality; customer satisfaction coefficient; attribute importance; added-value; value elasticity; value cultivation; attribute Life Cycles 


\section{Introduction}

In the attempt to understand and hence help to providing superior quality to clients the theory of attractive quality has emerged (Kano, 1984, 2001). This theory aims to understand and explain the roles different quality attributes play for customers and suggests a methodology for classification and understanding of quality at an attribute level seen from the customer's perspective. The Kano model has been widely practiced due to the fact that it visually captures a nonlinear relationship between product performance and customer satisfaction for the attractive quality attribute category (Xu et al, 2009).

However, in new product or service developments we do not have prior performance data and hence customer needs or wants are to be used as a proxy to ascertain and decide on which quality attributes the company should focus upon. Product and service development managers need for that purpose a reliable classification methodology to be used for understanding the impacts of new designed product and service quality attributes.

However, the Kano model is considered to have inherent weaknesses (Xu et al., 2009) and to be inefficient in identifying the rate of importance for each attribute (Yang, 2003). Therefore, as Witell, Löfgren and Dahlgaard (2013) argue, after the 'emergence, exploitation and explosion phases' in the evolution of the theory of attractive quality a new 'explanation phase' has emerged where the aim is to further develop the field of attractive quality creation. For that purpose Potra, Izvercian, Pugna and Dahlgaard (2015) suggested the so-called HWWP model which is a two variable diagram formed by the stated rate of importance of customer wants and needs and Berger's satisfaction coefficient (1993) as a proxy for 'the value added potential' of the product's difference quality attributes. With this new methodology the Kano categories were correlated with the customer stated rate of importance and Berger's satisfaction coefficient.

The HWWP model, however, did not always provide a clear and reliable assessment of the localization of all types of quality attributes due to its assumption of a uniform distribution representing variations between potential customer needs. Hence, the understanding of potential dynamics (life cycles) of the quality attributes may be uncertain due to the fact that the transition from one dimension to another seems to be done abruptly and with no clear strategic understanding about why and how? Based on this observation we came to the conclusion that a non-uniform partition model will be better to enhance the information analysis about consumer needs and wants to be used for new product and service developments.

The present article rejects the general uniform distribution assumption and suggests in stead a non-linear regression model as the basis for developing a strategic approach for analysing variations between potential customer needs in order better to understand what qualities should be further cultivated before product launch. The article discusses resulting value elasticity curves and argues that through the use of such curves, quality attributes can be more clearly separated and classified for a strategic understanding of their future dynamics (life cycles). The new approach is called "A Greenhouse Approach for Value Cultivation".

We regard the concept of value cultivation as a complement to the concepts of value creation (Santos et al, 2015) and value co-creation (Edvardsson \& Vargo, 2015). A key concept in value cultivation is care which easily can be understood when we relate it to a gardener's cultivation processes for creation of the most attractive flowers (e.g. roses) in the market. Without continuous care for the individual plants during the creation process only standard roses will be the result, but with continuous care much more attractive roses will be 
the result of the gardener's work. So value cultivation is the careful development of any product or service characteristics in order to optimize the value of those features.

In the next sections we will first shortly summarize advantages and dissadvantages of the Kano model, and after that we will present our suggestions for a new model called "the Greenhouse Model" which we have found useful for initiating further value cultivation. The Greenhouse Model will be presented and tested by using case study data in subsequent sections of this article and the value elasticity curves are estimated. After that follows a reflection section on the strategic implications of using the Greenhouse Model in the final design and development of new products or services. The article will end up with a conclusion section with suggestions for further research on how to refine further the Greenhouse Model.

\section{Short critical review of the Kano Model}

Customer needs should be analysed based on interpretations of the voice of the customer (Jiao and Chen, 2006), and after understanding customer preferences a classification and prioritization of the requirements is advised.

The strength of the Kano Model is its simplicity which makes it easy to understand and hence explain to others the roles different quality attributes play for customers. The classification methodology suggested for classification of product or a service attributes is also relatively simple to understand and explain. Because of its simplicity and its relevance, together with the need for such a model, the Kano Model soon became popular and spread to a variety of applications within production and later service areas (Wittel, Löfgren \& Dahlgaard; 2013).

The Kano model, however, was not equipped with a reliable quantitative assessment methodology, and the subjective classification of customer requirements lacks logical classification criteria, thus, providing limited decision support (Xu et al., 2009). In short, Kano (1984) defined customer requirements as quality attributes and classified them into six alternative categories based on the so-called Kano Questionnaire (see Table 1 below).

Selected customers' are asked to fill out such a questionnaire which has two questions, a functional question and a dis-functional question, for each quality attribute. Based on customers' perception on each pair of questions the classification follows directly from the questionnaire. For example if a selected customer has circled 1 (I like it that way) on the functional question and 4 on the dysfunctional question (I can live with it that way) then this quality attribute will be classified as an Attractive quality attribute.

By using such a questionnaire quality attributes are classified into one of the following six categories:

$\mathrm{A}=$ Attractive quality, $\mathrm{O}=$ One-dimensional quality, $\mathrm{M}=$ Must-be quality,

$\mathrm{I}$ = indifferent quality, $\mathrm{R}=$ Reverse quality, $\mathrm{Q}=$ Questionable category

It is surprising that Kano and his group did not suggest a supplementary quantitative measurement scale to help in differentiating between the various qualitative response combinations in the questionnaire. For example it follows from the questionnaire that three response combinations lead to Attractive quality, nine combination to Indifference quality, and three combinations to Must-be quality. We do not think that the three combinations leading to an Attractive quality classification have the same value to the customers, and the same with the other too broad classification categories. Hence, we suggest in this article a new 
quantitative measurement scale together with a new assessment model, the Greenhouse Model, to make the classifications more accurate and more understandable.

Table 1: Respondents' use of the Kano Questionnaire and the six alternative classifications

\begin{tabular}{|c|c|c|c|c|c|c|}
\hline \multirow{2}{*}{\multicolumn{2}{|c|}{$\begin{array}{l}\text { What is your } \\
\text { perception of the } \\
\text { existing Quality/ } \\
\text { Service Attribute? }\end{array}$}} & \multicolumn{5}{|c|}{$\begin{array}{l}\text { Dysfunctional Question: } \\
\text { What is your perception of the Quality Attribute if it is not } \\
\text { part of the product/service? }\end{array}$} \\
\hline & & \multirow{2}{*}{$\begin{array}{c}\text { I Like it } \\
\text { that way }\end{array}$} & \multirow{2}{*}{$\begin{array}{c}\text { It must be } \\
\text { that way } \\
\text { A }\end{array}$} & \multirow{2}{*}{$\begin{array}{c}\begin{array}{c}\text { I am } \\
\text { neutral }\end{array} \\
\mathrm{A}\end{array}$} & \multirow{2}{*}{$\begin{array}{c}\begin{array}{c}\text { I can live } \\
\text { with it that } \\
\text { way }\end{array} \\
\text { A }\end{array}$} & \multirow{2}{*}{$\begin{array}{c}\begin{array}{c}\text { I dislike it } \\
\text { that way }\end{array} \\
0\end{array}$} \\
\hline $\begin{array}{l}\mathbf{F} \\
\mathbf{U}\end{array}$ & $\begin{array}{l}\text { I Like it that } \\
\text { way }\end{array}$ & & & & & \\
\hline $\begin{array}{l}\mathbf{N} \\
\mathbf{C}\end{array}$ & $\begin{array}{l}\text { It must be } \\
\text { that way }\end{array}$ & $\mathrm{R}$ & 1 & 1 & 1 & $M$ \\
\hline $\begin{array}{l}\mathbf{T} \\
\mathbf{I}\end{array}$ & I am neutral & $\mathrm{R}$ & 1 & 1 & 1 & $M$ \\
\hline $\begin{array}{l}\mathbf{O} \\
\mathbf{N}\end{array}$ & $\begin{array}{l}\text { I can live with } \\
\text { it that way }\end{array}$ & $\mathrm{R}$ & 1 & 1 & 1 & $M$ \\
\hline $\begin{array}{l}\text { A } \\
\text { L }\end{array}$ & $\begin{array}{c}\text { I dislike it that } \\
\text { way }\end{array}$ & $\mathrm{R}$ & $\mathrm{R}$ & $\mathrm{R}$ & $\mathrm{R}$ & $Q$ \\
\hline
\end{tabular}

Wittel, Löfgren and Dahlgaard (2013) posed a question for the research community on how to support managers with knowledge on the theory of attractive quality and further how to develop the Kano methodology? Several scholars have in fact tried to build a new refined Kano model. Berger et al (1993), Matzler (1996), Newcomb and Lee (1997), Sampson and Showalter (1999), Martensen and Grönholdt (2001), Yang (2005), Xu et al. (2009), Kuo, Chen and Deng (2012), are some of the most important suggestions. All the suggested approaches have examined different Kano deficiencies striving to refine the existing Kano methodology. All those authors understood that the Kano categories are too unprecise for managerial practice and have provided various evaluation criteria for enhancing accuracy, but they mainly used the suggested approaches for analysing customer satisfaction/ dissatisfaction and importance criteria on quality attribute classifications of existing products and services.

What is needed now is a new approach which deepens its position into the theory of attractive quality and transforms it into a practical management tool to support new product and service design. Our suggested new approach is called „A Greenhouse Approach for Value Cultivation" and the development of this approach started with the development the Greenhouse Model explained in the following section.

\section{The Greenhouse Model}

Based on literature and empirical research, the suggested Greenhouse Model was a further development of the HWWP-Model (Potra, Izvercian, Pugna and Dahlgaard (2015). The model is constructed based on the following four main categories: Potential, Maintenance, Growth, and Wealth. Each of these categories can then be sub-divided into four sub-categories as can be seen in Figure 1. 
The background for using the name Greenhouse Model is that we have found it useful to compare the early processes in new product and service design with the processes a gardener follows when he cultivates new plants in a greenhouse. A gardener may have a lot of potential plants in his mind before he selects the seeds to be put into the soil. We can compare the potential plants and seeds with the first step in new product and service design - the idea generation phase. In this step there will always be a lot of ideas which have to be selected and cultivated or rejected for some reasons. At the end the gardener has to choose between the alternative seeds to be put into the soil, and the same is the case with a project team responsible for developing a new product or service.

After the seeds have come up as tiny or small plants the gardener will cultivate them further in another part of the greenhouse which we have called maintenance. All seeds need in the beginning to follow a simple cultivation process where the aim is to assure that the tiny plants will have enough space and get the right fertilizer for growing fast.

After a while the gardener will then select the plants which he expects the market will find most valuable and he will do special cultivation and care of those plants. The selected plants will be moved to a new part of the greenhouse - the growth area - which consists of plants that the gardener expects to have both high market value and also high importance because he has previous experiences with similar types of plants.

The wealth category consists of plants which are quite new to the market so the gardener expects that before market launch such plants will not be regarded as highly important but he expects that after a while the selected plants will surprise, charm and delight the customers and hence the market will regard such plants as both highly valuable and highly important.

When comparing with a project team's problems, challenges and processes when moving from the idea generation process to the blue print or prototype of a new product or service it is not too difficult to compare the project teams problems, challenges and processes with the gardener's problems, challenges and processes. Both the gardener and the project team need to have a deep understanding of the market, meaning customer needs and wants, and both need to develop and cultivate new or existing products or services which they expect will satisfy or exceed customer needs and wants. Both the gardener and the project team have the challenge on how to identify and satisfy latent needs.

The Greenhouse Model is, as shown in Figure 1 below, built upon the following two variables related to each attribute: 1 . Importance; 2. Value-added. Wherever quality attributes are first located in this diagram, the model offers invitations and opportunities for discussing strategies for future enhancement of the importance degree through promotion/customer education and increased value added through continuous renewal. 


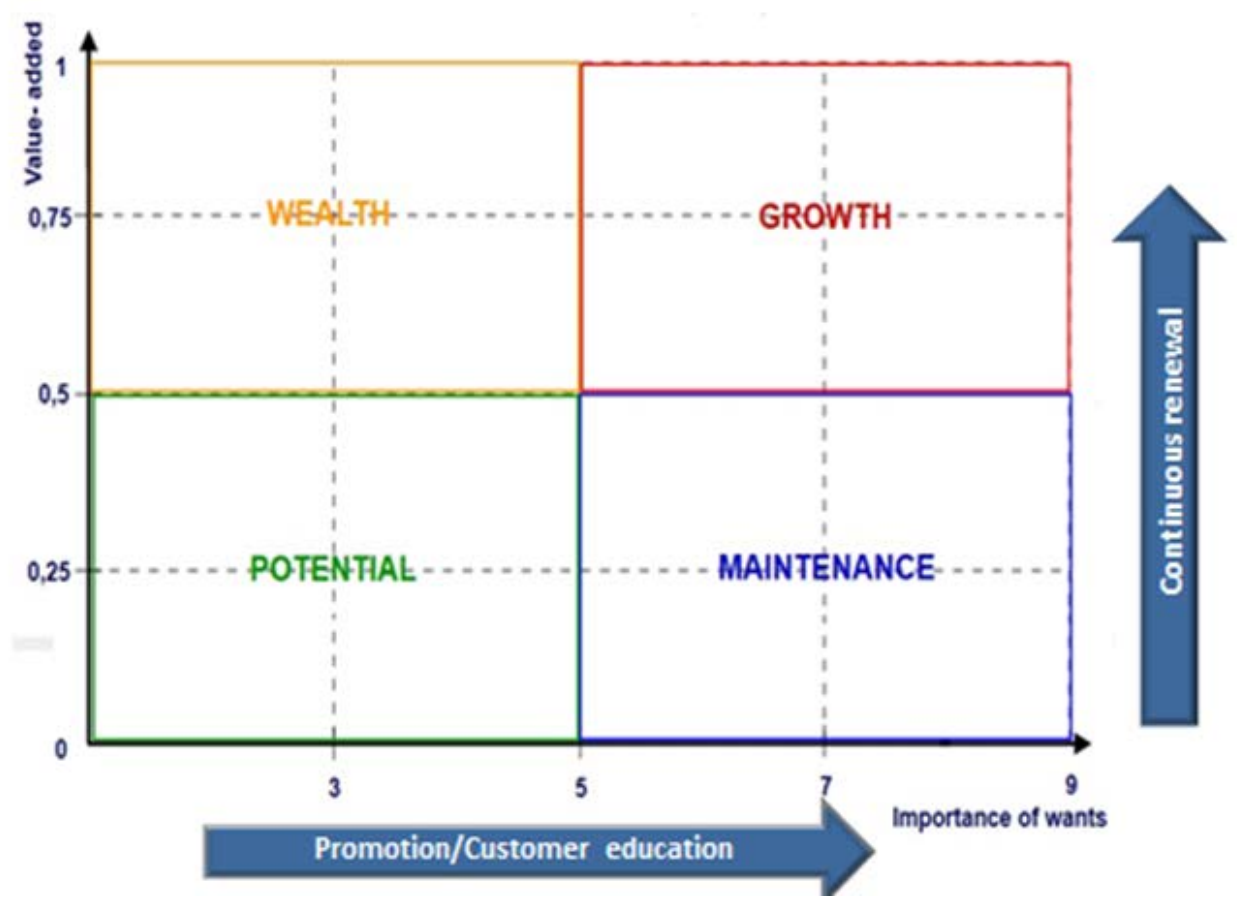

Figure 1: The Greenhouse Model

\section{Case study}

For a better understanding of the Greenhouse Model, we have re-tested Potra, Izvercian, Pugna and Dahlgaard (2015)'s case study data of a new web based customization service for a Romanian shoe manufacturing company to check if the results can be more acqurately analyzed by using the Greenhouse Model.

A Kano questionnaire was designed based on a pair of two questions for each specific service characteristic. Thereby, one question from each pair had a functional form (concerning the reaction of the customer if the product had that feature), and the second question had a dysfunctional form (concerning the customer's reaction if the product did not have that feature). A standard importance questionnaire was also used with the following scale: 1 (Not at all Important)... 9 (Extremely Important).

Before applying these two questionnaires an optimal proportional sample size was established. People from 18 to 35 years old who had demonstrated an increased online buying behaviour responded to the questionnaires, both by mail and by standard face-to-face oral interviews, totalling 166 individual valid responses.

Each quality attribute proposed for the customisation service was classified into one of the the Kano categories below (see also table 1 ). The few classification into $\mathrm{R}=$ Reverse category and $\mathrm{Q}=$ Questionable category were not included in this first data analyses.

$\mathrm{A}=$ Attractive quality category

$\mathrm{O}=$ One-dimensional category

$\mathrm{M}=$ Must-be quality category

$\mathrm{I}=$ Indifferent quality category

Together with the classification of each attribute into one of the above categories we also used distribution data for each attribute showing how many of the 166 respondents had evaluated the attribute as $\mathrm{A}, \mathrm{O}, \mathrm{M}$, or I. The distribution data was used to analyse the value-added 
criteria (the Y-variable of the model) based on Berger's (1993) customer satisfaction coefficient (SC) calculated as (1) below (see also the Apendix).

$$
S \in \frac{A+O}{A+O+M+I}
$$

The SC coefficient ranges from 0 to 1 ; the closer the value is to 1 , the higher is the influence on customer satisfaction as well as the customers' perceived value. In our previous study we used this coefficient to represent the value an attribute adds to a service (Potra, Izvercian, Pugna and Dahlgaard; 2015).

Table 2 presents for each attribute the identified Kano categories, the satisfaction coefficient (SC) as a measure of the value-added variable, the average customer stated importance and the main domains of the suggested Greenhouse Model.

Table 2: Quality Categories, Satisfaction Coefficient, Importance, Greenhouse Domains

\begin{tabular}{|l|l|c|c|c|c|}
\hline & Customization requirements & Category & $\begin{array}{c}\text { Value-added } \\
\text { (SC) }\end{array}$ & $\begin{array}{c}\text { Stated } \\
\text { Importance }\end{array}$ & $\begin{array}{c}\text { The Greenhouse } \\
\text { domains }\end{array}$ \\
\hline 1 & information clarity \&concision & $\mathrm{O}$ & 0.62 & 8.44 & Growth \\
\hline 2 & ease of use & $\mathrm{O}$ & 0.59 & 8.06 & Growth \\
\hline 3 & loading time optimization & $\mathrm{O}$ & 0.67 & 8.50 & Growth \\
\hline 4 & fast order confirmation & $\mathrm{M}$ & 0.49 & 8.63 & Maintenance \\
\hline 5 & modern design & $\mathrm{A}$ & 0.63 & 7.16 & Growth \\
\hline 6 & product 3D format & $\mathrm{A}$ & 0.80 & 7.28 & Growth \\
\hline 7 & image rotation & $\mathrm{A}$ & 0.71 & 7.68 & Growth \\
\hline 8 & customization storage & $\mathrm{A}$ & 0.58 & 6.89 & Growth \\
\hline 9 & view of other customer orders & $\mathrm{I}$ & 0.42 & 4.98 & Potential \\
\hline 10 & large n ${ }^{0}$ of customizable shoes & $\mathrm{A}$ & 0.65 & 6.76 & Growth \\
\hline 11 & customizing color & $\mathrm{O}$ & 0.76 & 8.73 & Growth \\
\hline 12 & customizing leather material & $\mathrm{A}$ & 0.77 & 7.87 & Growth \\
\hline 13 & customizing accessories & $\mathrm{A}$ & 0.66 & 6.92 & Growth \\
\hline 14 & payment options & $\mathrm{O}$ & 0.58 & 8.93 & Growth \\
\hline
\end{tabular}

Figure 2 below shows the Greenhouse Model with the 14 points of averages (Importance, Value $)=\left(\mathrm{X}_{\text {avg, }}, \mathrm{Y}_{\text {avg }}\right)$. As can be seen from Figure 2 and Table 2, the Greenhouse Model has refined the Kano Model classifications by taking into consideration the average importance which customers have assigned to the specific quality attributes and the average value (= SC) each attribute adds to customer satisfaction.

The Greenhouse Model assigned attribute six into the upper part of the Growth quadrant which indicates that the attribute is extremely valuable as a growing strategic advantage in future service market differentiations. The quality attributes 12 and 13 customization requirements - were both classified with the Kano model as attractive quality classifications, and the Greenhouse Model classified both of them as growth characteristics. The quality attribute 12 - customizing leather material - has a higher importance as well as a higher value added compared with quality attribute 13 (customizing accessories). This indicates that it may be a good strategic decision to invest more money and time to improve attribute 13 so that both value-added and importance are improved further and its position changes to the top position of the growth domain where attribute 12 right now is situated. 
As the above discussion clearly shows the Greenhouse Model offers a better decision support for new product or service designs than the Kano Model. However, the Greenhouse Model may even be further refined into a square shaped model which, together with a suggested new value measurement scale providing even better strategic information for managerial thought. The development of such a model will be discussed in the following sections.

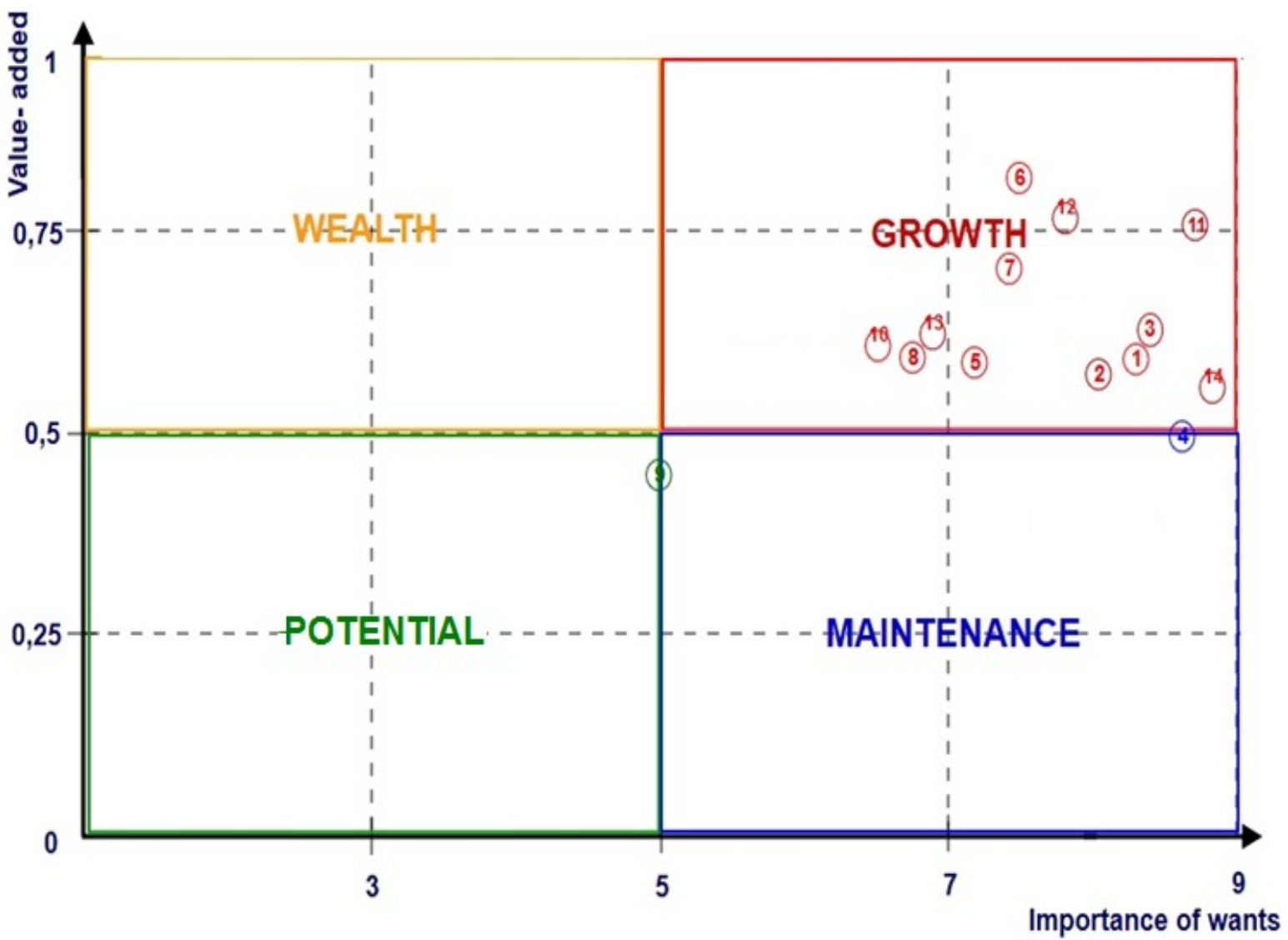

Figure 2: The Greenhouse model with respondents’ perception of Importance and Berger’s

Satisfaction Coefficient as Value Added variable

\section{The Refined Greenhouse Model with new Value Scale}

The value added variable computed with Berger's (1993) satisfaction coefficient (SC) provides an overall viewpoint of the averages (Importance, Value) $=\left(\mathrm{X}_{\text {avg, }}, \mathrm{Y}_{\text {avg }}\right)$, but the details about variation within the different categories are not exploited. Also, the attractive (A) and one-dimensional (O) categories are considered to provide equal customer satisfaction when calculating the satisfaction coefficient. Further, equation (1) does not take into consideration the values of the must-be (M) and indifferent (I) categories in the numerator indicating that customers regard $\mathrm{M}$ and $\mathrm{I}$ to have the same values. Hence it is questionable to use Berger's (1993) satisfaction coefficient as a value added variable. Instead we suggest in this section to use the entire information at our disposal by giving notes and ranks to all six categories depicted from the detailed questionnaire responses. 
Farquhar (1994) described adding value as a 'market value' adding distinctive benefits perceived by customers. Thus, the attractive category provides the highest benefits deserving the first rank in the added value criteria followed by the one-dimensional category. The mustbe category does not provide a significant added value (benefits) due to the fact that it refers to basic needs, and customer delight occurs only when customers' basic needs and expectations are exceeded (Naumann, 1995).

The indifferent category may at a first glance be considered as providing no value, but when we think about a product such as a mobile phone, in the design stage it has several quality attributes which are assessed differently by different customers. For most customers in developed countries a built-in camera is seen as a must-be attribute, a touch screen as onedimensional, a 3D function as attractive and an additional button for web navigation as indifferent. However, this does not mean that only the first three attributes provide value (benefits) and the last provides none. It does only mean that for the time being a 3D function provides less interesting benefits and therefore for the majority of users they are indifferent (they do not care too much if they have those benefits or not). Thus, we may consider the lowest value marks for the indifferent.

For the above reasons, we suggest to use the value scale suggested in table 3 below, and we will use this scale together with respondents' importance perceptions to estimate potential relationships between value and importance.

Table 3: Suggested Value scale related to respondents’ use of the Kano Questionnaire

\begin{tabular}{|c|c|c|c|c|c|c|}
\hline \multirow{2}{*}{\multicolumn{2}{|c|}{ Quality Attribute }} & \multicolumn{5}{|c|}{ Dysfunctional } \\
\hline & & \multirow{2}{*}{$\begin{array}{l}\text { I Like it that } \\
\text { way } \\
\text { Q } \\
0\end{array}$} & \multirow{2}{*}{$\begin{array}{c}\text { It must be } \\
\text { that way } \\
A \\
10\end{array}$} & \multirow{2}{*}{$\begin{array}{c}\text { I am neutral } \\
\text { A } \\
9\end{array}$} & \multirow{2}{*}{$\begin{array}{l}\begin{array}{l}\text { I can live } \\
\text { with it that } \\
\text { way } \\
\text { wa } \\
\text { A }\end{array}\end{array}$} & \multirow{2}{*}{$\begin{array}{c}\begin{array}{l}\text { I dislike it } \\
\text { that way }\end{array} \\
\text { O } \\
7\end{array}$} \\
\hline $\begin{array}{l}\mathbf{F} \\
\mathbf{U}\end{array}$ & $\begin{array}{l}\text { I Like it that } \\
\text { way }\end{array}$ & & & & & \\
\hline $\begin{array}{l}\mathbf{N} \\
\mathbf{C}\end{array}$ & $\begin{array}{l}\text { It must be that } \\
\text { way }\end{array}$ & $\begin{array}{l}\mathrm{R} \\
0\end{array}$ & $\begin{array}{l}1 \\
3\end{array}$ & $\begin{array}{l}1 \\
2\end{array}$ & $\begin{array}{l}1 \\
1\end{array}$ & $\begin{array}{c}M \\
6\end{array}$ \\
\hline $\begin{array}{l}\mathrm{T} \\
\mathbf{I}\end{array}$ & I am neutral & $\begin{array}{l}\mathrm{R} \\
0\end{array}$ & $\begin{array}{l}1 \\
0\end{array}$ & $\begin{array}{l}1 \\
0\end{array}$ & $\begin{array}{l}1 \\
0\end{array}$ & $\begin{array}{c}M \\
5\end{array}$ \\
\hline $\begin{array}{l}\mathbf{O} \\
\mathbf{N}\end{array}$ & $\begin{array}{l}\text { I can live with } \\
\text { it that way }\end{array}$ & $\begin{array}{l}\mathrm{R} \\
0\end{array}$ & $\begin{array}{l}1 \\
0\end{array}$ & $\begin{array}{l}1 \\
0\end{array}$ & $\begin{array}{l}1 \\
0\end{array}$ & $\begin{array}{c}M \\
4\end{array}$ \\
\hline $\begin{array}{l}A \\
L\end{array}$ & $\begin{array}{l}\text { I dislike it that } \\
\text { way }\end{array}$ & $\begin{array}{l}\mathrm{R} \\
0\end{array}$ & $\begin{array}{l}\mathrm{R} \\
0\end{array}$ & $\begin{array}{l}\mathrm{R} \\
0\end{array}$ & $\begin{array}{l}\mathrm{R} \\
0\end{array}$ & $\begin{array}{l}Q \\
0\end{array}$ \\
\hline
\end{tabular}

As seen from table 3 we used in this article an 11-point integer scale starting with zero given to Kano's R and Q categories and some I categories. It follows that the three A (Attractive) combinations are valued 10, 9 and 8. The $\mathrm{O}$ (One-dimensional) is valued 7. The three $\mathrm{M}$ (Must-be) combinations are valued 4, 5 and 6, three out of the nine I (Indifference) 
combinations are valued 1, 2 and 3, and the remaining I combinations are valued zero together with the $\mathrm{R}$ and Q-combinations. The qualitative description of these values follows below.

These qualitative descriptions were our first logical test when we selected the below value scale. The remaining part of this article shows also our first empirical tests of the reasonableness of this new value scale related directly to the Kano Questionnaire.

Value 10: It must be that way if it is not there but you like it if it is there. This should be the highest positive value an attribute can get. Hence value $=10$.

Value 9: You are neutral it if it is not there but you like it if it is there. This should be the $2^{\text {nd }}$ highest positive value an attribute can get. Hence value $=9$.

Value 8: You can live with it if it is not there but you like it if it is there. This should be the $3^{\text {rd }}$ highest positive value an attribute can get. Hence value $=8$.

Value 7: You dislike if it is not there but you like it if it is there". This should be the $4^{\text {th }}$ highest positive value an attribute can get. Hence value $=7$.

Value 6: You dislike if it is not there but it must be that way if it is there. This should be the $5^{\text {th }}$ highest positive value an attribute can get. Hence value $=6$.

Value 5: You dislike if it is not there but you are neutral it if it is there. This should be the $6^{\text {th }}$ highest positive value an attribute can get. Hence value $=5$.

Value 4: You dislike if it is not there but you can live with it if it is there. This should be the $7^{\text {th }}$ highest positive value an attribute can get. Hence value $=4$.

Value 3: It must be that way if it is not there but it must be that way if it is there. This should be the $3^{\text {rd }}$ lowest positive value an attribute can get. Hence value $=3$.

Value 2: You are neutral it if it is not there but it must be that way if it is there. This should be the $2^{\text {nd }}$ lowest positive value an attribute can get. Hence value $=2$.

Value 1: You can live with it if it not there but it must be that way if it is there. This should be the lowest positive value an attribute can get. Hence value $=1$.

The distribution of the 166 respondents' perceptions is shown for each attribute in table 4 below. It follows that for most of the attributes respondents' perceptions can be transformed to the higher values of the 11-point scale but for some attributes the transformation led to many low-value points such as attribute 9 more than $50 \%$ of the respondents' perceptions of this attribute lead to the lowest value point $(=0)$.

Table 4: Frequency Distribution of 166 respondents' perceptions related to new value scale

\begin{tabular}{|c|c|c|c|c|c|c|c|c|c|c|}
\hline \multirow{2}{*}{\multicolumn{2}{|c|}{$\begin{array}{c}\text { Service Requirement } \\
\text { (Quality Attributes) }\end{array}$}} & \multicolumn{9}{|c|}{ Value Scale } \\
\hline & & 10 & 9 & & 7 & 6 & 5 & 4 & 3 & $\mathbf{0}$ \\
\hline 1 & information clarity \&concision & & 5 & & 78 & 44 & 2 & & & 3 \\
\hline
\end{tabular}




\begin{tabular}{|c|c|c|c|c|c|c|c|c|c|c|c|}
\hline 2 & ease of use & & 6 & 18 & 76 & 41 & 1 & & 6 & 14 & 4 \\
\hline 3 & loading time optimization & 2 & 5 & 33 & 72 & 39 & & & 2 & 11 & 2 \\
\hline 4 & fast order confirmation & & 2 & 26 & 55 & 60 & 1 & & 6 & 14 & 2 \\
\hline 5 & modern design & & 50 & 45 & 10 & 1 & 1 & & 5 & 8 & 46 \\
\hline 6 & product 3D format & & 34 & 83 & 10 & 2 & & & 2 & 6 & 29 \\
\hline 7 & image rotation & 1 & 25 & 43 & 50 & 18 & & 1 & & 12 & 11 \\
\hline 8 & customization storage & & 20 & 51 & 28 & 16 & & 1 & 10 & 9 & 31 \\
\hline 9 & view of other customer orders & & 21 & 40 & 8 & 1 & 1 & & 5 & 3 & 87 \\
\hline 10 & large $\mathrm{n}^{0}$ of customizable shoes & 2 & 24 & 54 & 2 & 5 & 3 & & 4 & 7 & 46 \\
\hline 11 & customizing color & & 15 & 35 & 76 & 26 & & 1 & & 10 & 3 \\
\hline 12 & customizing leather material & 1 & 18 & 52 & 56 & 4 & 1 & & 3 & 8 & 23 \\
\hline 13 & customizing accessories & & 27 & 55 & 25 & 9 & & & 1 & 6 & 43 \\
\hline 14 & payment options & & 8 & 36 & 51 & 38 & 1 & & 6 & 15 & 11 \\
\hline
\end{tabular}

For building a square shaped model the importance of the wants/ needs has to be normalised. Table 5 below shows the averages of importance and value to be used in a square shaped model with normalized data, and figure 3 shows the square shaped Greenhouse Model where the averages of importance and value from table 5 has been used.

Table 5: Averages of Importance and Value with normalised scales $\{0 ; 1\}$

\begin{tabular}{|l|l|c|c|}
\hline \multicolumn{2}{|c|}{ Customization requirements } & $\begin{array}{c}\text { Importance } \\
\text { (Xavg) }\end{array}$ & $\begin{array}{c}\text { Value } \\
\text { (Yavg) }\end{array}$ \\
\hline 1 & information clarity \& concision & 0.84 & 0.62 \\
\hline 2 & ease of use & 0.80 & 0.60 \\
\hline 3 & loading time optimization & 0.85 & 0.65 \\
\hline 4 & fast order confirmation & 0.86 & 0.60 \\
\hline 5 & modern design & 0.71 & 0.54 \\
\hline 6 & product 3D format & 0.72 & 0.63 \\
\hline 7 & image rotation & 0.76 & 0.64 \\
\hline 8 & customization storage & 0.68 & 0.55 \\
\hline 9 & view of other customer orders & 0.51 & 0.35 \\
\hline 10 & large ${ }^{\text {0 }}$ of customizable shoes & 0.67 & 0.52 \\
\hline 11 & customizing color & 0.87 & 0.67 \\
\hline 12 & customizing leather material & 0.78 & 0.61 \\
\hline 13 & customizing accessories & 0.69 & 0.55 \\
\hline 14 & payment options & 0.89 & 0.58 \\
\hline
\end{tabular}




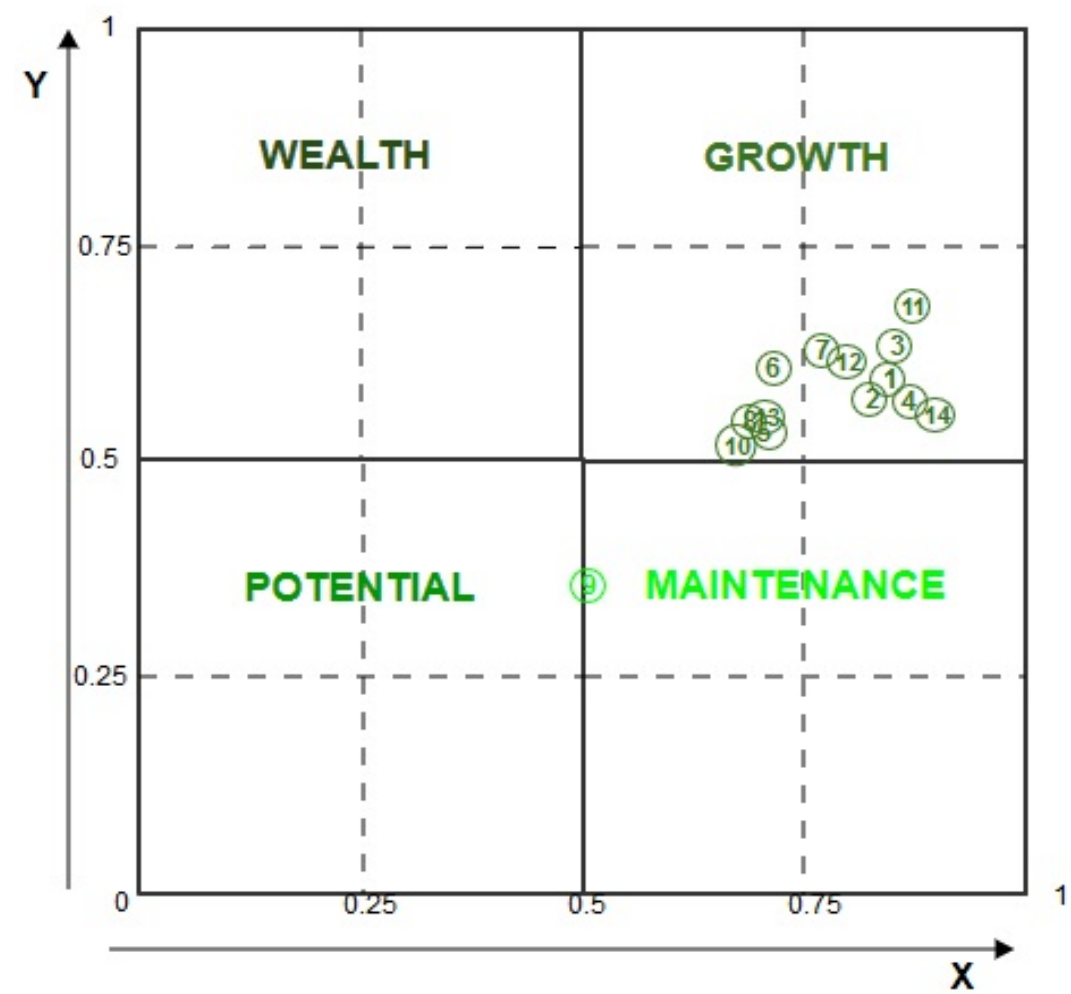

Figure 3: The square shaped Greenhouse Model with the averages $\left(\mathrm{X}_{\mathrm{avg}}, \mathrm{Y}_{\mathrm{avg}}\right)$ positioned

By comparing Figure 3 with Figure 2 we observe several significant changes which are caused by the different value scales used. For example we see no averages positioned in the top-right square of the model while Figure 2 showed that three attributes $(6,11,12)$ were positioned in this highly important and highly valuable part of the Growth domain. We observe that all average value measurements have been reduced compared with Figure 3.

\section{The Greenhouse Model based on a non-uniform distribution}

The second improvement we propose in this article regards the uniform assumption of the quality attributes' variation of the importance-value data $\{x, y\}$. Our statistical tests (using the interquartile range, the Gini coefficient, and the measure of Concentration) showed that for the case data the uniform assumption is unreasonable and hence the Greenhouse Model's assumptions should be refined into a non-linear partition assumption which will increase the entropy (value of information).

So, even if the strength of the first refined model - the Greenhouse Model - is its simplicity (based on the uniform distribution) we found it necessary to develop a new refined model which is based on a non-uniform partition of a unit square.

For choosing a non-uniform model we used regression analysis on the data from the four quality attributes 8, 9, 11 and 13 and used the following non-linear regression model:

$$
\mathrm{Y}=\mathrm{a} \cdot \mathrm{X}^{\mathrm{b}}
$$

Where: 
$\mathrm{Y}=$ Value of the attribute

$\mathrm{X}=$ Importance of the attribute

The equation (2) is similar with the constant elasticity demand function (Chen, 2007) represented as:

$$
\mathrm{Q}=\mathrm{a} \cdot \mathrm{P}^{\mathrm{b}}
$$

Where:

$$
\begin{aligned}
& \mathrm{P}=\text { price } \\
& \mathrm{Q}=\text { demand (measured as a quantity). }
\end{aligned}
$$

Economists understand that using (3) sections the two variables $\{P, Q\}$ through the diagonal or the point of unit elasticity where ED (elasticity demand) $=1$. All points above this region or point $(E D>1)$ are considered as elastic and all the points below this region or point $(E D<1)$ as inelastic. Hence, the same is true for the model (2) and also the model (4) below which will be used in the following for estimating potential relationships between customers' perceived importance $(\mathrm{X})$ and value $(\mathrm{Y})$.

For a $=1$ the model in (2) simplifies into:

$$
\mathrm{Y}=\mathrm{X}^{\mathrm{b}}
$$

This equation depends only on the parameter b:

For $\mathrm{b}=1.0, \mathrm{Y}=\mathrm{X}$, meaning that value is equal to importance and situated on the 45 degree diagonal. This means that elasticity between importance and value is equal to 1.0.

For $\mathrm{b}<1.0, \mathrm{Y}>\mathrm{X}$, meaning that value is higher than importance. This means that elasticity between importance and value is less than 1.0.

For $\mathrm{b}>1.0$ we have $\mathrm{Y}<\mathrm{X}$, meaning that value is lower than importance. This means that elasticity between importance and value is higher than 1.0.

For $b=1$ the model in (2) simplifies into the linear model below:

$$
\mathrm{Y}=\mathrm{a} \cdot \mathrm{X}
$$

This equation depends only on the parameter as follows:

For $\mathrm{a}=1.0, \mathrm{Y}=\mathrm{X}$, meaning that value is equal to importance and situated on the 45 degree diagonal. This means that elasticity between importance and value is equal to 1.0.

For a $<1.0, \mathrm{Y}<\mathrm{X}$, meaning that value is lower than importance. This means that elasticity between importance and value is less than 1.0.

For a $>1.0$ we have $\mathrm{Y}>\mathrm{X}$, meaning that value is higher than importance. This means that elasticity between importance and value is higher than 1.0.

The relation of models (2), (4) and (5) to the economic domain gives the Greenhouse Model a practical managerial thought by making the division into elastic and inelastic regions where value elasticity is equal to one if the relation between importance and value follows the 
diagonal, greater than one if the relation follows a curve (or a section of a curve) above the diagonal and less than one if the relation follows a curve (or a section of a curve) below the diagonal.

\section{Estimation of Model (4) - Nonlinear Regression Models without intercept}

We used the new value scale data for the attributes 8, 9, 11 and 13 to test the hypothesis assumption that data follows the nonlinear regression model in (4) with random variations. The P-values in table 6 strongly support this assumption. Table 6 shows the estimated regression coefficients and the coefficient of determination which are relatively high.

Table 6: Model (4) - nonlinear case without intercept

\begin{tabular}{|c|c|c|c|c|}
\hline Attribute & Attribute name & $\begin{array}{c}\text { Regression } \\
\text { Coefficients }\end{array}$ & $\begin{array}{c}\text { Coefficient of } \\
\text { determination }\end{array}$ & P-value \\
\hline 8 & customizing accessories & $\mathrm{b}=2.14$ & 0.781 & $10^{-13}$ \\
\hline 9 & view other customer orders & $\mathrm{b}=1.99$ & 0.806 & $10^{-13}$ \\
\hline 11 & customizing color & $\mathrm{b}=2.42$ & 0.710 & $10^{-13}$ \\
\hline 13 & payment options & $\mathrm{b}=2.42$ & 0.789 & $10^{-13}$ \\
\hline
\end{tabular}

The estimated regression models are all situated below the diagonal which means that the variation in the data follows an elastic curve even if some data points may be regarded as outliers in relation to the shown models (see figures 4-6). The value added data points equal to 0.05 shown in the diagrams are necessary approximations to the zero values in the 11-point value scale used because of the statistical software used for the estimation used logarithm transformations.

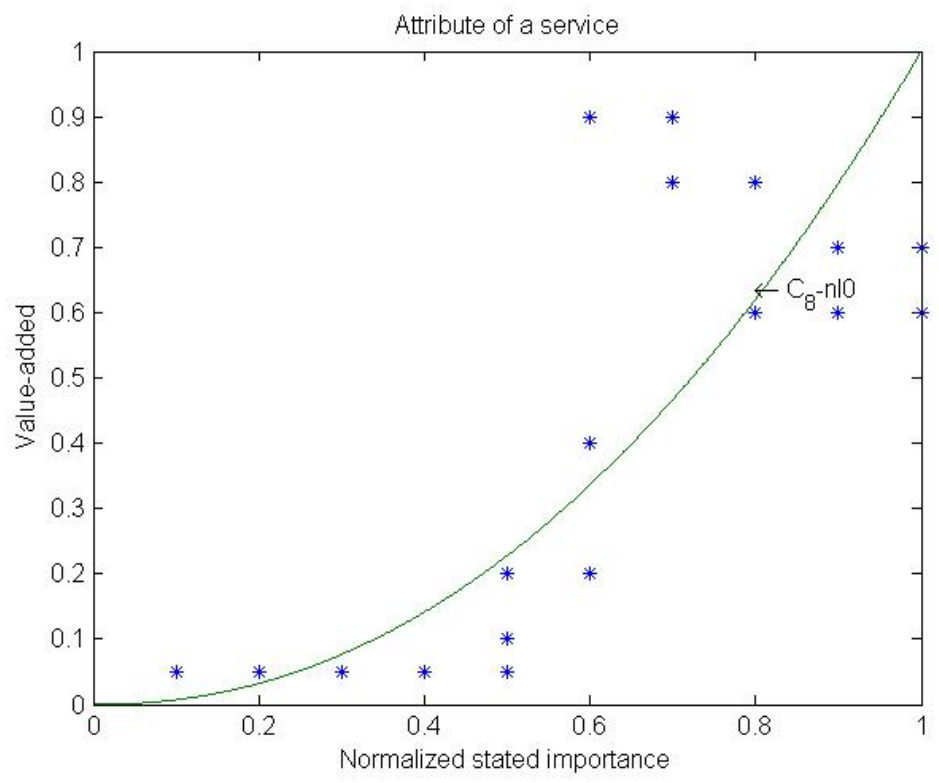

Figure 4: Attribute 8 (customizing accessories) 


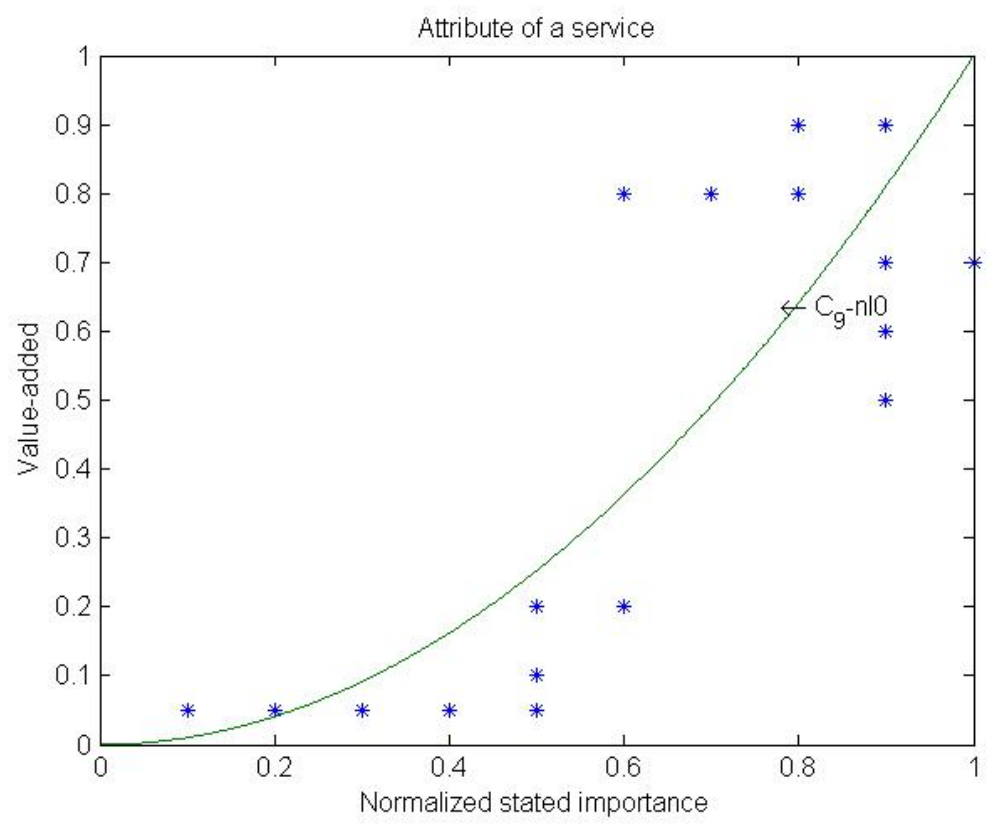

Figure 5: Attribute 9 (view of other customer orders)

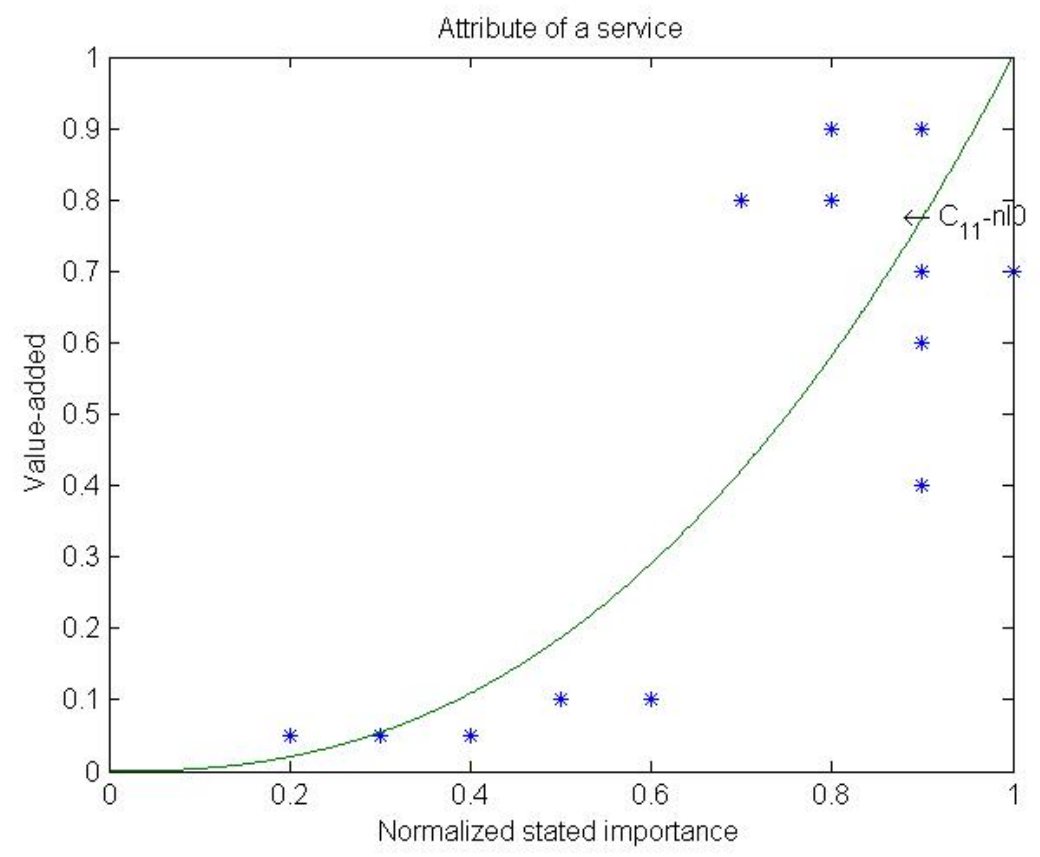

Figure 6: Attribute 11 (customizing color) 


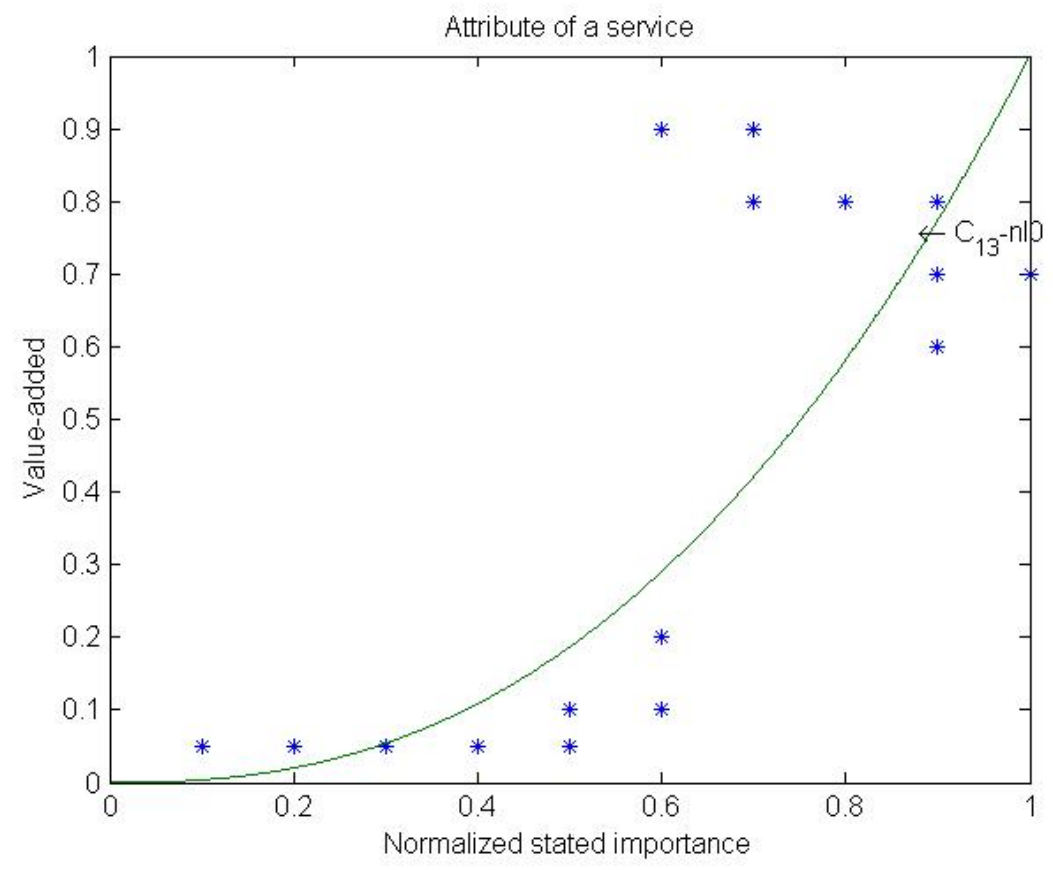

Figure 7: Attribute 13 (payment options)

In summary we regard the estimation results as a support for the practical use of the simple non-linear model in (4). All of the estimated models showed a relatively high degree of explanation (= determination coefficient). However, we could in some of the estimations observe some strange positions of data points with the highest values. For example in figures 4 and 7 the highest values (9 and 8) had lower importance than the medium values (6 and 7). This observation indicates that there may be a need to fine tune the scale for the highest as well as the medium values. As said above this fine tuning and retesting in relation to the applicability of the used non-linear model in (4) is going on right now and could not be finalized to be included in this article.

\section{Strategic Implications?}

So what are the strategic implications and possibilities of using models like (2), (4) and (5) together with the Greenhouse Model in the process of the further cultivation of selected attributes where the overall aim is to maximize the final design's capability to affect customers' perception of value added? Potential answers to this complex question will be discussed in the following.

In brief, improvements of a quality attribute measured with $\mathrm{X}=$ importance and $\mathrm{Y}=$ added value situated in an elastic region may have a high potential to satisfy customers. Small improvement of attributes situated in this region may have substantial effect on customers' perception of added value. Conversely, improvements of a quality attribute situated in an inelastic region may have less potential to create substantial effects on customers' perception of added value.

However, as indicated in figure 1 of the Greenhouse Model, the strategic improvement process may also comprise selection of attributes which for some reason need to be promoted and selected customers educated. Indications of the need for such activities are: 1. Outliers, 
meaning data points outside the normal variation around the estimated regression models, 2 . Low value data. 3. Low importance data. Attribute 9 has all three indications.

From table 3 we can see that 87 out of 166 respondents valued attribute 9 (view other customer orders) with a zero value, and we can also see from the table that 21 respondents valued the possibility to view examples of what other customers might previously have ordered with a value of 8 and 40 respondents valued this possibility with a value of 7 . Why this variation in respondents' value perceptions? Maybe the negative respondents did not understand how such a possibility may help them when they try to customize the product they consider to buy? Is it possible to promote this possibility or educate in some way the negative customer segment related to this attribute so that most of the negative customers can see the value for themselves and in this way improve such potential customers' perceptions of both importance and value? Is it possible to further develop the web based customization service so that it includes possibilities for changing the negative customers' attitudes in relation to this attribute?

We have no answers to these questions but design specialists have to find the answers to such questions before they decide what should be done with this quality attribute during the final cultivation/ improvement of the prototype and market launch of the product. The answers are crucial for the cultivation and further development of this attribute so that it can be moved from being just an attribute which potentially give value to customers to an attribute which is regarded as a growth attribute which customers perceive as highly valuable and important.

The Greenhouse Model showing the attribute averages of $(\mathrm{X}, \mathrm{Y})=$ (Importance, Value) as perceived by potential customers (as Figure 3) may be the best tool to use first when starting the strategic process for deciding on the final decisions and processes for what attributes to further cultivate and develop. Figure 3 shows clearly that attribute 9 should have a special attention but also other of the attributes seems to have possibilities for further cultivations. For example attribute 14 have the highest average importance of the 14 analysed attributes $(=0.89)$ but average value is relatively low $(=0.58)$. Why? What kind of improvements is needed to increase customers' value perceptions so that the position of this attribute may move to the upper-right square of the weapon domain?

\section{Conclusions}

Because the Kano Model has a qualitative nature and hence gives limited decision support in engineering design the Greenhouse Model was developed as an explanatory paradigm and a more useful option to support strategic decision making. The Greenhouse Model together with new developed methods for measuring quality attributes' value effects opened for developing a new practical approach to assess and understand the potential cultivation of the value added as well as the importance of selected quality attributes.

The suggested non-linear regression model to be used for understanding the variation of customers' perceptions of importance and value gives the possibility to estimate the relation between those two variables and to use those relations as elasticity curves. The elasticity curves sections the model in elastic and inelastic regions and provides a natural trajectory for possible life cycle analysis through further value cultivations. Life cycle analysis has previously been discussed only in relation to existing products and services. As we said in the introduction of this article, what is needed now is a new approach which 
deepens its position into the theory of attractive quality and transforms the theory into a practical management tool to support new product and service design.

The elasticity curves, overlapping the Greenhouse Model's four main domains (Potential, Maintenance, Growth and Wealth), facilitate a clearer understanding of potential customer needs and satisfaction. The elasticity curves together with the Greenhouse Model give a strategic overview of quality attributes' further cultivation and development opportunities, so that new products or services can be more accurately designed to fit customer needs. Managers will be able to plan with more precision future cultivation and development stages of each quality attribute.

In conclusion, the present research offered a Greenhouse Approach for further value cultivation based on the non-uniform partition with elasticity curves which improves the understanding and the classification of customer needs and especially the added value assessments necessary for an important decision-making tool in new product or service design.

Based on our comprehensive analyses of the case example we conclude that the application of the Greenhouse Model with the application of estimated elasticity curves envisages a better managerial and strategic understanding regarding classifications of quality attributes and the strategic selection and forecasting of potential effects of the potential value cultivation.

The new value measuring 11-point scale used in the article is linked directly to the Kano Questionnaire and tries to utilize all information available instead of just classifying attributes into one of the six potential qualitative categories (A, O, M, I, R and Q). Berger (1993) suggested also to use a quantitative scale by using the satisfaction coefficient (SC) which only uses 4 out of 6 classification categories in the Kano Model (A, O, M, and I categories). We used his quantification method as a start and observed that this approach did not use all information in the Kano Questionnaire.

Even if the suggested value measuring scale is, to the best of our knowledge, the first to link the scale directly to the 25 combinations of the Kano Questionnaire (see Table 1) there is, as we observed when estimating the non-linear model in (4), a need for further tests to fine tune the used 11-point scale. Further, there is also a need to develop new methods for measuring of the value and importance variables before and after the new developed service has been experienced by the customers.

\section{References}

Berger C. et al., (1993), "Kano’s methods for understanding customer-defined quality", The Centre for Quality Management Journal, Vol.2, No.4, 3-36

Chen, C-H., (2007), Price Elasticity of Demand, Principles of Microeconomics, Lecture 3, September 10 2007, ocw.mit.edu/.../14...2007/.../14_01_lec03.pdf

Edvardsson, B. Å. \& Vargo, S. L. (2015), "Value Co-Creation”, in Dahlgaard-Park, S.M. (ed.), The SAGE Encyclopedia of Quality and the Service Economy, pp. 836-840, SAGE Publications, Thousand Oaks, California, US

Farquhar, P.H., (1994), "Strategic Challenges for Branding", Marketing Management, Vol.3, No.2, 8-15

Jiao, J and Chen, C H., (2006), "Customer requirement management in product development: a review of research issues", Concurrent Engineering: Research and Applications, Vol.14, No.3, 173-185

Kano N. et al., (1984), "Attractive quality and Must-be quality", The Journal of the Japanese Society for Quality Control, Vol.14, No.2, 39-48 
Kano, N., (2001), "Life cycle and creation of attractive quality”, paper presented at the fourth International QMOD Conference on Quality Management and Organisational Development, University of Linkoping

Kuo Y.F., Chen J.Y \& Deng W.J., (2012), "IPA-Kano model: A new tool for categorizing and diagnosing service quality attributes", Total Quality Management\& Business Excellence, Vol.23, No.7-8, 731-748

Martensen A. \& Grönholdt L., (2001), "Using employee satisfaction measurement to improve people management: An adoption of Kano's quality types", Total Quality management, Vol.12, No.7-8, 949-954

Matzler et al., (1996), "How to delight your customers", Journal of Product and Brand Management, Vol.5, No.2, 6-18

Naumann, E. (1995), "Creating Customer Value. The Path for Sustainable Competitive Advantage", Thompson executive Press, Cincinnati, $\mathrm{OH}$

Potra, S., Izvercian, M., Pugna, A. and Dahlgaard, J., (2015), "The HWWP, a refined IVAKano model for designing new delightful products or services", Total Quality management \& Business Excellence, in press

Newcomb J \& Lee M., (1997),"Applying the Kano methodology to meet customer requirements: NASA's microgravity science program", Quality Management Journal, Vol.4, No.3, 95-110

Sampson, S.E. and Showalter, M.J., (1999), "The Performance-Importance Response Function: Observations and Implications", The Service Industries Journal, Vol.19, No.3, 1-25

Santos, G., Rebelo, M. F. Silva, R. \& Lopes, N. (2015), in Dahlgaard-Park, S.M. (ed.), The SAGE Encyclopedia of Quality and the Service Economy, pp. 840-844, SAGE Publications, Thousand Oaks, California, US

Löfgren M. and Dahlgaard J.J., (2013), "Theory of attractive quality and the Kano methodology - the past, the present, and the future",Total Quality management \& Business Excellence, Vol.24, No11-12, Special Issue, 1241-1252

Xu, Q., Jiao, R.J., Yang, X., Helander, M., and Halimahtun, K., (2009), "An analytical Kano model for customer need analysis", Design Studies, Vol.30, No.1, 87-110

Yang C.C., (2003), "Improvement actions based on the customers' satisfaction survey", Total Quality Management \& Business Excellence, Vol.14, No.8, 919-930

Yang, C.C., (2005), "The Refined Kano's Model and its Application", Total Quality Management, Vol.16, No.10, 1127-1137

\section{Appendix}

Calculation of Berger's Customer Satisfaction/ Dissatisfaction Coefficients (1993)

\begin{tabular}{|c|c|c|c|c|c|c|c|}
\hline $\begin{array}{l}\text { Product } \\
\text { Requirements } \\
\text { (example) }\end{array}$ & $\mathbf{A}$ & $\mathbf{O}$ & $\mathbf{M}$ & $\mathbf{I}$ & Category & $\begin{array}{c}\text { CS: } \\
\underline{\mathbf{A}+\mathbf{O}} \\
\mathbf{A + O + M}+\mathbf{I}\end{array}$ & $\begin{array}{c}\text { CD: } \\
\frac{\mathbf{O}+\mathbf{M}}{\mathrm{A}+\mathbf{O}+\mathbf{M}+\mathbf{I}}\end{array}$ \\
\hline Edge grip & 7 & 33 & 50 & 10 & $\mathbf{M}$ & 0.40 & -0.83 \\
\hline
\end{tabular}




\begin{tabular}{|l|c|c|c|c|c|c|c|}
\hline Ease of turn & 11 & $\mathbf{4 6}$ & 31 & $\mathbf{1 2}$ & $\mathbf{O}$ & 0.57 & -0.78 \\
\hline Servioce & $\mathbf{6 6}$ & 22 & 3 & 9 & $\mathbf{A}$ & 0.89 & -0.25 \\
\hline
\end{tabular}

CS = Customer Satisfaction Coefficient

CD = Customer Dissatisfaction Coefficient 